\title{
Protocol Deviation Reference Identifier
}

National Cancer Institute

\section{Source}

National Cancer Institute. Protocol Deviation Reference Identifier. NCI Thesaurus. Code C87993.

A character or string used to name, or characterize a protocol deviation reference. 